\title{
Expectancies and memory for an emotional film fragment: a placebo study
}

Citation for published version (APA):

van Oorsouw, K. I. M., \& Merckelbach, H. L. G. J. (2007). Expectancies and memory for an emotional film fragment: a placebo study. American Journal of Psychology, 120(2), 287-301.

https://doi.org/10.2307/20445399

Document status and date:

Published: 01/01/2007

DOI:

10.2307/20445399

Document Version:

Publisher's PDF, also known as Version of record

\section{Please check the document version of this publication:}

- A submitted manuscript is the version of the article upon submission and before peer-review. There can be important differences between the submitted version and the official published version of record.

People interested in the research are advised to contact the author for the final version of the publication, or visit the DOI to the publisher's website.

- The final author version and the galley proof are versions of the publication after peer review.

- The final published version features the final layout of the paper including the volume, issue and page numbers.

Link to publication

\footnotetext{
General rights rights.

- You may freely distribute the URL identifying the publication in the public portal. please follow below link for the End User Agreement:

www.umlib.nl/taverne-license

Take down policy

If you believe that this document breaches copyright please contact us at:

repository@maastrichtuniversity.nl

providing details and we will investigate your claim.
}

Copyright and moral rights for the publications made accessible in the public portal are retained by the authors and/or other copyright owners and it is a condition of accessing publications that users recognise and abide by the legal requirements associated with these

- Users may download and print one copy of any publication from the public portal for the purpose of private study or research.

- You may not further distribute the material or use it for any profit-making activity or commercial gain

If the publication is distributed under the terms of Article $25 \mathrm{fa}$ of the Dutch Copyright Act, indicated by the "Taverne" license above, 


\title{
Expectancies and memory for an emotional film fragment: A placebo study
}

\author{
KIM VAN OORSOUW AND HARALD MERCKELBACH \\ Maastricht University
}

This study investigated whether positive ("memory-enhancing”) and negative ("memory-impairing") placebos may enhance and undermine, respectively, memory of a film fragment. After watching an emotional film fragment, participants were assigned to a "memory-enhancing" placebo group $(n=30)$, control group $(n=30)$, or "memory-impairing" placebo group $(n=30)$. Only participants who believed in the placebo effect were included in the analyses. In the positive placebo group, memory for the film fragment was better than that of participants who received negative placebos or control participants. Participants in the negative placebo group made more distortion errors than participants in the positive placebo or control group. Our findings show that people's expectancies about their memory may affect their memory performance. These results may have implications for both clinical practice and the legal domain.

Several studies suggest that expectancies can affect memory performance. According to Ponds, Van Boxtel, and Jolles (2000), older adults often evaluate their cognitive functioning more negatively than younger people, when in fact there is no substantial difference between these groups in their performance on objective memory tasks. Meanwhile, the pessimistic expectations of older adults (e.g., fear of dementia) may undermine their daily memory functioning in cognitive demanding situations. Other studies have found that beliefs about memory functioning-socalled metamemory beliefs_-can be experimentally manipulated such that people come to evaluate their memories to be less available. For example, Winkielman, Schwarz, and Belli (1998) showed that successful retrieval of many childhood memories can paradoxically induce the belief in participants that their memory of childhood is poor. This paradoxical effect has to do with participants attributing the cognitive effort needed for memory retrieval to the quality of their childhood memories (see also Belli, Winkielman, Read, Schwarz, \& Lynn, 1998; Winkielman \& Schwarz, 2001). van Oorsouw and Merckelbach (2006) found that the paradoxical effect of memory retrieval is not an inert side effect but can undermine subsequent performance on an autobiographical memory task. 
Expectancy effects have been investigated with the use of placebos (Brown, 1998). A placebo is an inactive substance that is presented to participants or patients as an active drug. In pharmacologic studies, a placebo condition usually is used to differentiate genuine effects related to the pharmacologic properties of a drug from the expectancy effects that occur when patients are administered a drug. When the patient's health improves after administration of a placebo, this improvement is not attributable to the intrinsic properties of the drug but to explicit beliefs or expectancies about the effects of the placebo. Although this is often called the placebo effect, in a strict sense such an effect can be established only when patients in a placebo condition improve more than those in a no-treatment control group (Kirsch \& Lynn, 1999; StewartWilliams \& Podd, 2004).

Although in clinical trials, physiologic (e.g., blood pressure) and emotional (e.g., pain sensation) placebo effects have been well documented (e.g., De Craen, Kaptchuk, Tijssen, \& Kleijnen, 1999; De Jong, van Baast, Arntz, \& Merckelbach, 1996; Pope \& McNally, 2002), placebo effects on cognitive functioning (e.g., memory) have been studied less well. One exception is the study of Assefi and Garry (2003), who found that the belief of having consumed alcohol, when in fact the drink was a nonalcoholic beverage, made participants more susceptible to misleading postevent information. Assefi and Garry argued that the social context is critical to the placebo effect they found because no effect of the alcohol placebo was found on memory for control events (i.e., no misinformation). That is, the mere belief that they had consumed alcohol in combination with suggested misinformation may have increased participants' tendency to accept misinformation from the experimenter. Accordingly, Assefi and Garry concluded that "alcohol placebos did not affect memory per se, but influenced participants' tendency to capitulate to suggestions made by the experimenter" (p. 79).

Another study in this domain is that by Kvavilashvili and Ellis (1999), who investigated the placebo effect on cognitive performance in a design that did not include social suggestions provided by others. These authors gave participants a placebo capsule and told them explicitly that it would improve or impair their memory for a list of words. They only found significant effects on actual performance in the condition in which memory impairment expectancies had been created. Here, participants recalled fewer previously learned words than participants in the control or positive placebo condition (i.e., a memory quantity effect), and they also tended to make more commission errors (i.e., a memory accuracy effect). For participants who had received "memory-improving" instructions, no positive placebo effect on memory performance was evident. In contrast, Green, Taylor, Elliman, and Rhodes (2001) did find a positive placebo 
effect when studying the effects of glucose on cognitive functioning. Participants who received glucose performed better than participants who were given a placebo and were told it was a placebo. However, another group, which was given a placebo but was told it was glucose, also performed better than the told-placebo group. This indicates that the mere suggestion of receiving glucose when in fact it is a placebo may improve cognitive functioning.

So far, the published studies on placebos and memory have relied heavily on static memory material (e.g., word lists, slides). The aim of the present study was to investigate expectancy effects of "memory-enhancing" and "memory-impairing" placebos on memory for an emotional film fragment. Based on previous studies examining placebo effects and memory, we predicted that in comparison to a no-treatment control group, "memoryenhancing" placebos would improve memory for the film fragment (i.e., more correctly recalled details and less commission and distortion errors than in the other groups), whereas "memory-impairing" placebos would worsen memory for the film fragment (i.e., fewer correctly recalled details and more commissions and distortions than in the other groups). We measured three types of dependent variables: objective memory performance, subjective memory estimates, and subjective memory effort. The last variable was included to control for reversed placebo effects. These occur when positive placebos impair and negative placebos improve participants' memory as a result of decreased or increased effort in retrieving information (Kvavilashvili \& Ellis, 1999). If reverse placebo effects occurred, one would also expect group differences in the amount of effort, with the positive placebo group reporting less effort than the negative placebo group.

The scarce experimental literature on placebos and memory shows that one has to differentiate between two levels at which effects might occur. One level is that of objective performance (e.g., memory performance on a word list task). The other level is that of expected or perceived efficacy of the placebo and has more to do with subjective beliefs and expectancies (i.e., metamemory). Both levels might be partially or completely dissociated. For example, in the Kvavilashvili and Ellis (1999) study, those who had a positive placebo tended to report that it had improved their performance, whereas those who had a negative placebo tended to report that it had undermined their performance. Yet at the level of objective memory performance, only negative placebos were found to undermine free recall of learned words. Likewise, in a study by Greenwald, Spangenberg, Pratkanis, and Eskenazi (1991), participants who were given subliminal self-help tapes to improve their memory subsequently indicated that their memory had improved, although this was not reflected in objective measures of memory. Although subjective and objective placebo effects 
might be dissociated, one may safely assume that objective placebo effects occur only to the extent that participants believe that the placebo will be or has been effective to begin with. Assuming that objective placebo effects critically depend on subjective expectancies, the current study included participants on basis of the latter variable. That is, only participants who believed the placebo to be effective were included in the main analysis.

Previous placebo studies (Assefi \& Garry, 2003; Kvavilashvili \& Ellis, 1999) manipulated expectancies at or before encoding. In such design, beliefs about "memory-enhancing" or "memory-impairing" drugs could affect encoding, retrieval, or both. In the current study, we administered placebos after encoding of the emotional film material. The reason for doing so was our interest in real-life situations such as eyewitnesses reporting about a crime that they saw. In the forensic literature, one can find many examples of authors claiming that drugs such as barbiturates may help eyewitnesses or defendants to recover previously lost memories about an emotional event (for a review, see Kihlstrom, 1998). One simple explanation for these memory-facilitating phenomena is that they reflect positive placebo effects.

\section{EXPERIMENT}

\section{METHOD}

\section{Design and procedure}

The study was approved by the standing Ethical Committee of the Faculty of Psychology, Maastricht University. Participants ( $N=90$; 73 women, 17 men) volunteered to participate in an experiment that was announced as a study on memory-improving and memory-impairing drugs. Participants were first screened by telephone. This telephone interview was conducted to enhance the belief that real drugs were being tested. Thus, during the telephone interview, participants were asked whether they were pregnant, suffered from epilepsy or depression, and were using medication (for a similar procedure, see Kvavilashvili \& Ellis, 1999). When all these questions were answered negatively, they were allowed to participate in the study. Participants were instructed not to drink beverages containing alcohol or caffeine up to $4 \mathrm{hr}$ before the experiment because this could affect memory performance. We selected participants who believed the placebo instructions.

When participants came to the lab some days later, they were informed about the procedure. They were told that they might be assigned to one of the two groups that were going to test a new drug, but they might also be assigned to a control group that would not test any drugs. Participants filled out informed consent forms and were asked whether they had any questions about the drugs they might be asked to take. The first part of the experiment, the encoding phase, consisted of watching a film fragment. Participants were told that they were about to watch an emotional film fragment. Nothing was mentioned about any upcoming memory 
tests for this fragment. Next, expectations about memory were manipulated by administering the "memory-enhancing" (positive) or "memory-impairing" (negative) placebos. Finally, memory for the encoded material was tested.

The film fragment (duration about $3 \mathrm{~min}$ ) was an emotional scene taken from the movie American History X. The fragment was about a neo-Nazi shooting two black men who were trying to steal his car. This film fragment has been used in previous studies in our lab (Giesbrecht, Geraerts, \& Merckelbach, in press; Smeets, Candel, \& Merckelbach, 2004). On the basis of this previous work, we have developed a scoring protocol for evaluating memory data about the fragment. After participants had seen the fragment, they were asked to rate on two $100-\mathrm{mm}$ visual analog scales (VASs; anchors $1=$ not emotional/realistic, 100 = very emotional $/$ realistic) how emotional and realistic they thought the fragment was. Next, participants were randomly assigned to one of the three groups by drawing an envelope from a box. The experimenter was blind to the content of the envelopes. The envelope contained instructions and a placebo capsule in the experimental groups or only instructions in the control group. Participants were asked to open the envelope, read the instructions, and take the capsule, if any, with some water. In the positive placebo group, instructions were as follows: "You are in the memory-enhancing group. You are testing a homeopathic drug, called MEMOLIN, which is known to stimulate memory performance. It increases the transmission of serotonin and acetylcholine in the brain, compounds that are important for memory processes." The negative placebo group received the following instructions: "You are in the memory-impairing condition. You are testing a food supplement, called SERUNUL [from Kvavilashvili \& Ellis, 1999], of which the most important side effect is that it briefly suppresses memory performance. It reduces the transmission of serotonin and acetylcholine in the brain, compounds that are important for memory processes." The following instructions were similar for both groups: "The drug has no bodily side-effects we know of. However, if you do experience any side effects, we ask you to report them in the exit interview. It takes approximately 30 minutes for the drug to cross the blood-brain barrier. So, after 30 minutes from now we will start with the memory testing. After two to three hours, the drug will lose its effect. Please take the capsule orally with some water and fill out the question below and close the envelope. Do not tell the experimenter in which condition you are." After participants had read the instructions, they answered a question that was on the instruction form. The question was about how much effect they expected the capsule to have on their memory performance. Instructions in the envelope the control groups received read as follows: "You are in the control group, which means that you are not testing any drugs. However, similar to participants in the other two groups you are asked to wait for 30 minutes. After 30 minutes the memory testing will start."

After participants had closed the envelope, an interval of $30 \mathrm{~min}$ followed. During the interval, all participants filled out a few questionnaires that were not related to memory and will not be considered further here. When participants had finished the questionnaires within the 30-min period, they were asked to remain in the room and were given some magazines to read. During this stage of the experiment, participants were never told that the memory test would pertain to the 
film fragment. To enhance the belief that real drugs were used, blood pressure was measured immediately before the placebo was administered (baseline) and a second time after the 30-min interval had elapsed, when the drugs had supposedly crossed the brain barrier. Participants were told that it was necessary to closely monitor their physiologic responses to the drug or that blood pressure served as a control measure in case they would not receive a drug (i.e., in the control group). Therefore, baseline blood pressure was measured for all participants before they knew to which group they were assigned. During the 30-min interval, the experimenter stayed in the room with the participant, who was told that this was done so that quick action could be taken in case he or she experienced any side effects. After $30 \mathrm{~min}$ had passed, participants were told that their memory for the film fragment would be tested. They were asked to write down everything they could remember of the film fragment. Participants were instructed to describe the events, people, and surroundings in as much detail as possible. Finally, participants underwent an exit interview. As part of this interview, they completed questions about how much effort they had put into completing the memory test (anchors: $0=$ no effort, 7 = very much effort), how effective they judged the drug to have been in affecting their memory (anchors: $0=$ no effect, $7=$ very powerful), and whether they had any ideas about the research questions. After this, participants were fully debriefed and were given their credit hour.

\section{Statistical analysis}

Blood pressure was analyzed using a 3 (groups) $\times 2$ (baseline vs. follow-up) analysis of variance (ANOVA) with repeated measures on the last factor. Free recalls of the film fragment were subjected to a one-way ANOva with the three groups (i.e., positive placebo, negative placebo, and control group) as independent factor. To identify specific differences between groups, follow-up pairwise comparison $t$ tests with Bonferroni corrections $(\alpha=.01)$ were carried out. Ratings of emotionality and realism of the film fragment, expected effect, and experienced influence were evaluated with one-way ANOVAs or independent sample $t$ tests in case comparisons involved only the two experimental groups.

\section{RESULTS}

\section{Participants}

In total, 90 undergraduate students ( 73 women, 17 men) participated in the experiment. Their mean age was 19.7 years $(S D=2.5$, range, $17-32$ years). Participants received 1 course credit hour for their participation. Only participants who expected the drug to be more than slightly effective (ratings higher than 3) were included in the main analysis. Participants who did not believe in the memory-enhancing or memory-impairing properties of the placebos were excluded. ${ }^{1}$ Indeed, there was a significant interaction effect between beliefs about the placebo's effectiveness (ratings of 3 or less or ratings greater than 3) and the placebo groups' (positive or negative) free recall performance, $F(1,58)=7.37, p<.05$. This shows that 
the placebo's effect on objective memory performance depended on the a priori beliefs participants held. Therefore, further analyses were based on participants who expected the placebo to be effective. More specifically, there were 13 participants ${ }^{2}$ in the positive placebo group, 15 in the negative placebo group, and 30 in the control group. The mean expected effect (anchors: $0=$ no effect, $7=$ very powerful) was $4.4(S D=0.5)$ and 4.5 $(S D=0.5)$ in the memory-enhancing and memory-impairing groups, respectively, $t(26)<1.0$.

\section{Blood pressure}

Although blood pressure was measured primarily to create the impression that real drugs were being administered, it was also used as a measure of arousal. To examine whether blood pressure changed as a result of placebo administration, a repeated-measure ANOva was conducted for systolic and diastolic parameters separately. We found a main effect of time for systolic pressure, $F(1,54)=14.56, p<.05$, and diastolic pressure, $F(1,54)=5.81, p<.05$, but no interaction effect (group $\times$ time) for systolic, $F(2,54)<1.0$, or diastolic, $F(2,54)=1.97, p=.15$, pressure. ${ }^{3}$ Also, we did not find main effects of group, both $F_{\mathrm{S}}(1,54)<1.0$. That is, the two placebo groups and the control group displayed a decrease in blood pressure over time, but this decrease was not modulated by the treatment given to participants.

\section{Memory for the film fragment}

The groups did not differ with regard to their emotionality, $F(2,57)<1.0$, or realism, $F(2,57)<1.0$, ratings of the film fragment. The mean emotionality and realism ratings of all groups were above 75 on the $100-\mathrm{mm}$ VAS.

Based on extensive previous work in our lab with the stimulus material (see Giesbrecht, Geraerts, \& Merckelbach, in press; Smeets, Candel, \& Merckelbach, 2004), a scoring device was used to evaluate participants' free recall. Two independent raters, who were blind as to the treatments given to each participant, coded free recall protocols for the presence of 38 crucial pieces of information in the film fragment that would be important for a police investigation (e.g., "The neo-Nazi shoots," "The brother was watching," "The men shot down were black"). For every correctly reported piece of information, participants received 1 point. To obtain a total free recall score, the number of correctly reported pieces of information was summed (maximum $=38$ ). Free recall scores were transformed into proportions. Also, the number of commission and distortion errors was calculated. Following the definitions that can be found in Gudjonsson and Clare's (1995) work on false memories and suggestibility, a commission error was defined as the introduction of an entirely new but incorrect element, that is, an element that was not part of the 
film fragment (e.g., "the neo-Nazi pulled one of the men out of the car," when in fact the car got away). A distortion error was defined as a major change in details of an existing event (e.g., "the neo-Nazi had a swastika tattooed on his upper arm," when in fact a swastika was tattooed on his chest, or "the younger brother was wearing shorts," when in fact he was wearing long pants). The total number of distortion and commission errors was summed.

Free recall accounts were coded by the first author and a research assistant. Pearson correlations between both raters were .86 for number of correctly recalled items, .68 for number of commission errors, and .75 for distortion errors (all $p \mathrm{~s}<.01$ ). Because interrater correlations for errors were low, we included in our analyses only commission and distortion errors that were identified by both raters.

Proportions of correctly recalled information and number of commissions and distortions are shown in Table 1. For proportion correctly recalled information, a one-way ANova yielded a significant main effect of groups, $F(2$, $57)=8.03, p<.01, \eta_{p}^{2}=.23$. Bonferroni corrected post hoc tests $(\alpha=.01)$ showed that participants in the positive placebo group recalled more correct information than either participants in the negative placebo group, $t(26)=2.91, p=.01$, or participants in the control group, $t(41)=3.59$, $p=.001$. The negative placebo and control groups did not differ from each other, $t(43)<1.0$. No group differences were found for number of commission errors, $F(2,57)<1.0, \eta_{p}{ }^{2}=.03$, indicating that positive or negative expectations about memory did not lead to more or fewer commissions than when no such expectations were induced. For distortion errors, however, significant group differences did occur, $F(2,57)=3.62, p<.05, \eta_{p}{ }^{2}=.12$. Participants in the negative placebo group made more distortion errors than control participants, $t(43)=2.44, p=.02$, two tailed, and tended to make more distortion errors than the positive placebo group, $t(26)=1.84$, $p=.04$, one-tailed. The positive placebo group and control group did not differ from each other in terms of distortion errors, $t(26)<1.0 .^{4}$

Table 1. Proportions of correct free recall and number of commission and distortion errors $(S D)$ for the positive placebo $(n=13)$, negative placebo $(n=15)$, and control $(n=30)$ groups

\begin{tabular}{|c|c|c|c|}
\hline & Positive placebo & Negative placebo & Controls \\
\hline Proportion free recall & $0.50(0.11)^{\mathrm{a}, \mathrm{b}}$ & $0.41(0.05)$ & $0.38(0.09)$ \\
\hline Number of commissions & $0.38(0.50)$ & $0.73(0.96)$ & $0.56(0.68)$ \\
\hline Number of distortions & $0.69(0.63)^{\mathrm{a}}$ & $1.33(1.11)^{\mathrm{c}}$ & $0.66(0.71)$ \\
\hline
\end{tabular}

${ }^{\mathrm{a}} p<.05$ between positive placebo and negative placebo group.

${ }^{\mathrm{b}} p<.05$ between positive placebo and control group.

${ }^{c} p<.05$ between negative placebo and control group. 


\section{Self-report measures}

At the end of the experiment, when participants were asked to evaluate how the drug had influenced their memory, both placebo groups rated the drug as having been effective in the suggested direction. There were no group differences in this respect, $t(26)=1.12, p=.27$, with means of $3.1(S D=1.5)$ and $2.5(S D=1.0)$ for the positive and negative placebo group, respectively. The groups did not differ in the amount of effort they put into completing the memory tasks, $F(2,57)=1.69, p=.19$, with means of $4.8(S D=1.6), 4.0(S D=1.4)$, and $4.2(S D=1.5)$ in the positive, control, and negative group, respectively.

There were no significant correlations between the effect that participants a priori ascribed to the drug and the influence on memory that was ascribed to the placebo a posteriori, $r=.10, p=.60$. Thus, it was not the case that participants automatically reported an effect on memory when they expected the drug to be effective..$^{5}$

\section{DISCUSSION}

The results of this study can be summarized as follows. First, taking a placebo capsule had no physiologic effects on blood pressure. Second, positive placebos had an effect on memory quantity in the sense that participants in the positive placebo group recalled more correct information about the film fragment than participants in the negative placebo or control group. Third, although groups did not differ in number of commission errors, participants in the negative placebo group tended to make more distortion errors than participants in the positive placebo or control group. Thus, negative placebos had a limited effect on memory accuracy.

Our results show that the mere suggestion that a drug improves memory has a positive effect on memory performance. Participants in the "memoryenhancing" placebo group recalled 9\% more correct information than participants in the "memory-impairing" placebo group and 12\% more than control participants. As for self-reported changes (i.e., the memory effect participants ascribed to the placebo afterwards), we found both positive and negative placebos to be mildly effective. Participants who received memory-enhancing instructions (i.e., positive placebo group) reported an increase in memory performance to the same extent as participants in the negative placebo group reported a decrease in memory performance. Thus, like Kvavilashvili and Ellis (1999), we found placebo effects in terms of self-reported changes in memory. However, in contrast to Kvavilashvili and Ellis, we found the positive placebo group to have higher levels of correct recall rather than the negative placebo group having lower levels 
of correct recall. That we could not replicate the negative placebo effect on memory quantity reported by Kvavilashvili and Ellis may have to do with the fact that we administered the placebo after encoding, whereas Kvavilashvili and Ellis gave it before encoding. The memory-undermining effect of negative placebos in their study may have been caused by a decrease in attention, affecting memory encoding and consolidation. In our study, participants did not know what type of "drug" they would receive when the film fragment was shown to them. Therefore, it is impossible that expectancies about the placebo interfered with their encoding of the stimulus material. Perhaps, then, negative placebos undermine memory quantity only to the extent that they interfere with encoding, whereas positive placebos improve quantity only to the extent that they enhance retrieval. This issue of how different types of placebos interfere with different memory stages warrants further study.

Our results replicate those of Kvavilashvili and Ellis (1999) in that we too found that negative placebos tend to compromise memory accuracy. It has to be added, though, that the memory-undermining effect on accuracy that we found was limited to distortions and was not apparent for commission errors. Furthermore, the effect of negative placebos on distortions errors was only borderline significant when Bonferroni corrections were made. Another explanation as to why we were unable to find a memoryundermining effect of negative placebos on recall or commission errors may have to do with the type of stimulus material we used. Although we do not know how stimulus material might interact with placebo expectancies, the fact remains that our stimulus material was emotional and dynamic, whereas that of Kvavilashvili and Ellis was neutral and static (i.e., word lists). Perhaps the highly effective encoding of emotional material (Dolan, 2002; Hamann, 2001) may have been a safeguard against full-blown commission errors, and this might explain why we did not detect a connection between negative placebos and commissions. Clifasefi, Garry, Harper, Sharman, and Sutherland (in press) also argue that placebo effects depend on the type of stimulus material. Clearly, the precise interactions between placebo effects, expectancies, and memory for different types of stimulus material deserve further research.

We can only speculate about the mechanisms responsible for the memory quantity effect of positive placebos and the memory accuracy effect of negative placebos. There were no differences in subjectively reported retrieval effort, and therefore this factor cannot explain differential memory performance. Although it is often argued that drug effects on memory are caused by increases or decreases in arousal and attention (Tinkelberg \& Taylor, 1984), these factors are unlikely to be responsible for the placebo effects on actual memory performance obtained in the current study. After all, there were no differences in arousal (i.e., blood pressure) between 
the two placebo groups after administration of the capsules, indicating that manipulating expectations about the drug did not have any differential effects on arousal. Before and after placebo administration, the average blood pressure for all groups was within the normal range (i.e., systolic pressure less than 130, diastolic pressure less than 80), although all three groups displayed higher blood pressure during the first session. One explanation for this higher blood pressure could be the emotional film fragment, because negative emotional stimuli are known to increase cardiovascular responses (Honda, Masaki, \& Yamazaki, 2002). Another explanation for the higher blood pressure before placebo administration could be the anticipation of potential drug intake. In any case, the decrease in arousal over time was not caused by the placebo per se. With these considerations in mind, we suspect that the placebo effects on actual memory performance can best be understood in terms of cognitive expectancy, attribution, and source monitoring (for a review, see Kirsch \& Lynn, 1999). For example, in the negative placebo group, participants might have thought that distortion errors are acceptable because of the memory-undermining drug they had had. A similar pattern was reported in Assefi and Garry's (2003) study in which participants who had had an "alcohol" placebo were more likely to accept incorrect information. In a recent study, Clifasefi et al. (in press) noted that when participants had been given "memory-enhancing" placebos, they were less susceptible to misleading information than participants who had been told they received a placebo. These authors argued that their positive placebo findings are the product of more stringent source monitoring, which would make it easier to detect misleading information and to resist misleading suggestions and false memories.

Admittedly, an expectancy interpretation does not fully account for the whole range of findings in our study. The fact that negative placebos tended to have an undermining effect on memory accuracy rather than memory quantity suggests that apart from expectancies, other factors play a role in how placebos affect objective memory performance. As mentioned before, one such factor could be the extent to which placebos interact with encoding, retrieval, and source monitoring.

Several limitations of the current study deserve brief comment. To begin with, it is possible that in the positive placebo group, participants rehearsed material of the film fragment, thereby leading to superior memory performance. On the other hand, during the 30-min interval, participants did not yet know that the upcoming memory test would be about the film fragment. Nevertheless, because we did not use a demanding filler task, we cannot exclude the possibility that our groups differed in their rehearsal activities. Second, the placebos in our study were harmless-looking sugar capsules. Although our analyses included only participants who said they 
believed the placebo had been effective, a more powerful manipulation of expectancies might occur if one administered placebos with a distinct taste or a genuine but harmless side effect (Kirsch \& Lynn, 1999). With stronger expectancies created, fewer participants would have to be excluded, resulting in larger groups and more powerful tests. Third, in our study memory testing was done within one session. It would be important to know how persistent placebo effects are on actual memory performance. To this end, a study involving multiple test sessions would be needed. Fourth, our work and that of others (Kvavilashvili \& Ellis, 1999; Green et al., 2001) makes plain that expectancies set up by placebos may affect objective memory performance, but it does little to explain how these effects might occur. For example, in our study we did not include confidence ratings as an index of source monitoring decisions. Meanwhile, it is conceivable that placebo-induced expectancies affect primarily the confidence people have in their memory reports. Obviously, this issue warrants further study.

In sum, placebo participants in our study thought that the placebo had affected their memory (i.e., self-reported memory improvement or impairment was evident). Thus, a posteriori, participants reported a slight improvement (i.e., positive placebo) or impairment (i.e., negative placebo). As Kvavilashvili and Ellis (1999) noted, self-reported effects for both types of placebos are not uncommon. Indeed, placebo effects reported in pharmacologic studies are revealed more often with subjective reports of changes in mood or pain and less so with objective physiologic changes (Ross \& Olson, 1981). From a clinical point of view, subjective metamemory effects are of some importance. For example, our finding that the mere expectation of memory impairment or improvement leads to corresponding changes in self-reported memory performance is relevant to the treatment of older adults who have pessimistic ideas about their memory. The participants who showed changes in actual memory performance were healthy and intelligent undergraduates. It might well be the case that placebo effects on memory performance become even more powerful in heterogeneous samples (e.g., people with health complaints). With this in mind, it would be both interesting and important to conduct placebo memory studies in clinical groups. Consider older adults who ruminate about their fear of Alzheimer disease (e.g., Ponds et al., 2000) or depressive people who have undergone electroconvulsive therapy (e.g., Coleman et al., 1996). In these groups, firm beliefs that something is wrong with one's memory might result in a self-fulfilling prophecy. Our findings lead one to wonder whether such a self-fulfilling prophecy can be reversed by giving these people positive placebos. Or consider perpetrators who report amnesia for the crime they have committed. If their amnesia is expectancy based (i.e., the perpetrator has convinced himself that his amnesia is profound), then changing these expectations using a "memory-enhancing" placebo could 
perhaps resolve the amnesia. Finally, placebos could be used in eyewitnesses who have difficulties remembering what they have seen. Our results suggest that positive placebos may lead to better retrieval of the witnessed event, without compromising memory accuracy. These practical issues deserve further investigation.

\section{Notes}

Correspondence about this article should be addressed to Kim van Oorsouw, Department of Experimental Psychology, Maastricht University, P.O. Box 616, 6200 MD, Maastricht, The Netherlands (e-mail: k.vanoorsouw@psychology.unimaas.nl). Received for publication October 20, 2005; revision received January 26, 2006.

1. A subsequent analysis of memory performance of the remainder of participants who did not expect the drugs to be effective ( $n=15$ in the positive placebo group and $n=15$ in the negative placebo group) yielded no between-group differences on proportions of correctly recalled information, $t(28)<1.0$, number of commission errors, $t(28)<1.0$, or number of distortion errors, $t(28)=1.12$, $p=.27$. This shows that beliefs people have about placebos are a crucial factor when it comes to the effectiveness they attribute to them.

2. Two participants did not answer the question about how effective they believed the placebo would be. They were excluded from further analyses.

3. Blood pressure measures for one participant were missing because of equipment failure.

4. Because both experimental groups were small, one could argue that the effects on free recall or distortion errors could have been caused by one or two participants with extreme free recall or distortion scores. To this end, $z$ scores were calculated to locate participants with extreme scores $(z<-2$ or $>2)$. When the two participants with extreme scores were excluded from the analysis, free recall scores were unaffected ( $p=.02$, two-tailed). We did not remove outliers from our analyses of distortions because all participants made $0,1,2$, or 3 distortion errors. Against this background, any definition of an outlier would be arbitrary.

5. Interestingly, the opposite was true for the group that was excluded from the analysis because they did not believe the drug would be effective. In this group, there was a significant correlation between expected effect and reported effect, $r=.60, p<.01$. That is, pessimistic beliefs about the drug's effectiveness in this group did affect their reports afterward.

\section{References}

Assefi, S. L., \& Garry, M. (2003). Absolut(R) memory distortions: Alcohol placebos influence the misinformation effect. Psychological Science, 14, 77-80.

Belli, R. F., Winkielman, P., Read, J. D., Schwarz, N., \& Lynn, S. J. (1998). Recalling more childhood events leads to judgments of poorer memory: Implications for the recovered/false memory debate. Psychonomic Bulletin E Review, 5, 318-323.

Brown, W. A. (1998). The placebo effect. Scientific American, 278, 90-96. 
Clifasefi, S. L., Garry, M., Harper, D. N., Sharman, S. J., \& Sutherland, R. (in press). Psychotropic placebos create resistance to the misinformation effect. Psychonomic Bulletin E् Review.

Coleman, E. A., Sackeim, H. A., Prudic, J., Devanand, D. P., McElhiney, M. C., \& Moody, B. J. (1996). Subjective memory complaints prior to and following electroconvulsive therapy. Biological Psychiatry, 39, 346-356.

De Craen, A. J., Kaptchuk, T. J., Tijssen, J. G., \& Kleijnen, J. (1999). Placebos and placebo-effects in medicine: A historical overview. Journal of the Royal Academy of Social Medicine, 92, 511-515.

De Jong, P. J., van Baast, R., Arntz, A., \& Merckelbach, H. (1996). The placebo effect in pain reduction: The influence of conditioning experiences and response expectancies. International Journal of Behavioral Medicine, 3, 14-29.

Dolan, R. J. (2002). Emotion, cognition, and behavior. Science, 298, 1191-1194.

Giesbrecht, T., Geraerts, E., \& Merckelbach, H. (in press). Dissociation, memory commission errors, and heightened autonomic reactivity. Psychiatry Research.

Green, M. W., Taylor, M. A., Elliman, N. A., \& Rhodes, O. (2001). Placebo expectancy effects in the relationship between glucose and cognition. British Journal of Nutrition, 86, 173-179.

Greenwald, A. G., Spangenberg, E. R., Pratkanis, A. R., \& Eskenazi, J. (1991). Double-blind tests of subliminal self-help audiotapes. Psychological Science, 2, 119-122.

Gudjonsson, G. H., \& Clare, I. C. H. (1995). The relationship between confabulation and intellectual ability, memory, interrogative suggestibility and acquiescence. Personality and Individual Differences, 19, 333-338.

Hamann, S. (2001). Cognitive and neural mechanisms of emotional memory. Trends in Cognitive Sciences, 5, 394-400.

Honda, A., Masaki, H., \& Yamazaki, K. (2002). Influence of emotion-inducing film stimuli on autonomic response specificity. Japanese Journal of Physiological Psychology and Psychophysiology, 20, 9-17.

Kihlstrom, J. F. (1998). Exhumed memory. In S. J. Lynn \& K. M. McConkey (Eds.), Truth in memory (pp. 3-31). New York: Guilford.

Kirsch, I., \& Lynn, S. J. (1999). Automaticity in clinical psychology. American Psychologist, 54, 504-515.

Kvavilashvili, L., \& Ellis, J. A. (1999). The effect of positive and negative placebos on human memory performances. Memory, 7, 421-437.

Ponds, R. W. H. M., Van Boxtel, M. P. J., \& Jolles, J. (2000). Age-related changes in subjective cognitive functioning. Educational Gerontology, 26, 67-81.

Pope, K. W., \& McNally, R. J. (2002). Nonspecific placebo effects explain the therapeutic benefit of magnets. Scientific Review of Alternative Medicine, 6, 10-13.

Ross, M., \& Olson, J. M. (1981). An expectancy-attribution model of the effects of placebos. Psychological Review, 88, 409-437.

Smeets, T., Candel, I., \& Merckelbach, H. (2004). Accuracy, completeness, and consistency of emotional memories. American Journal of Psychology, 117, 595609 . 
Stewart-Williams, S., \& Podd, J. (2004). The placebo effect: Dissolving the expectancy versus conditioning debate. Psychological Bulletin, 130, 324-340.

Tinkelberg, J. R., \& Taylor, J. L. (1984). Assessment of drug effects on human memory functions. In L. R. Squire \& N. Butters (Eds.), Neuropsychology of memory (pp. 213-223). New York: Guilford.

van Oorsouw, K., \& Merckelbach, H. (2006). When remembering causes forgetting: The paradoxical effect of remembering. Manuscript submitted for publication.

Winkielman, P., \& Schwarz, N. (2001). How pleasant was your childhood? Beliefs about memory shape inferences from experienced difficulty of recall. Psychological Science, 12, 176-179.

Winkielman, P., Schwarz, N., \& Belli, R. F. (1998). The role of ease of retrieval and attribution in memory judgments: Judging your memory as worse despite recalling more events. Psychological Science, 9, 124-126. 